\title{
Proinflammatory Cytokine IL-6 and JAK-STAT Signaling Pathway in Myeloproliferative Neoplasms
}

\author{
Vladan P. Čokić, ${ }^{1}$ Olivera Mitrović-Ajtić, ${ }^{1}$ Bojana B. Beleslin-Čokić, ${ }^{2}$ \\ Dragana Marković, ${ }^{1}$ Marijana Buač, ${ }^{1}$ Miloš Diklić, ${ }^{1}$ Nada Kraguljac-Kurtović, ${ }^{3}$ \\ Svetozar Damjanović, ${ }^{2,4}$ Pavle Milenković, ${ }^{1}$ Mirjana Gotić, ${ }^{3,4}$ and Puri K. Raj ${ }^{5}$ \\ ${ }^{1}$ Institute for Medical Research, University of Belgrade, 11129 Belgrade, Serbia \\ ${ }^{2}$ Clinic of Endocrinology, Diabetes and Diseases of Metabolism, Clinical Center of Serbia, 11000 Belgrade, Serbia \\ ${ }^{3}$ Clinic of Hematology, Clinical Center of Serbia, 11000 Belgrade, Serbia \\ ${ }^{4}$ Medical Faculty, University of Belgrade, 11000 Belgrade, Serbia \\ ${ }^{5}$ Division of Cellular and Gene Therapies, Center for Biologics Evaluation and Research, Food and Drug Administration, \\ Silver Spring, MD 20993, USA
}

Correspondence should be addressed to Vladan P. Čokić; vl@imi.bg.ac.rs

Received 26 June 2015; Revised 2 September 2015; Accepted 9 September 2015

Academic Editor: Hannes Neuwirt

Copyright (c) 2015 Vladan P. Čokić et al. This is an open access article distributed under the Creative Commons Attribution License, which permits unrestricted use, distribution, and reproduction in any medium, provided the original work is properly cited.

\begin{abstract}
The recent JAK1/2 inhibitor trial in myeloproliferative neoplasms (MPNs) showed that reducing inflammation can be more beneficial than targeting gene mutants. We evaluated the proinflammatory IL- 6 cytokine and JAK-STAT signaling pathway related genes in circulating $\mathrm{CD} 34^{+}$cells of MPNs. Regarding laboratory data, leukocytosis has been observed in polycythemia vera (PV) and $J A K 2 \mathrm{~V} 617 \mathrm{~F}$ mutation positive versus negative primary myelofibrosis (PMF) patients. Moreover, thrombocytosis was reduced by JAK2V617F allele burden in essential thrombocythemia (ET) and PMF. 261 significantly changed genes have been detected in PV, 82 in ET, and 94 genes in PMF. The following JAK-STAT signaling pathway related genes had augmented expression in CD34 $4^{+}$cells of MPNs: CCND3 and IL23A regardless of JAK2V617F allele burden; CSF3R, IL6ST, and STAT1/2 in ET and PV with JAK2V617F mutation; and AKT2, IFNGR2, PIM1, PTPN11, and STAT3 only in PV. STAT5A gene expression was generally reduced in MPNs. IL-6 cytokine levels were increased in plasma, as well as IL-6 protein levels in bone marrow stroma of MPNs, dependent on JAK2V617F mutation presence in ET and PMF patients. Therefore, the JAK2V617F mutant allele burden participated in inflammation biomarkers induction and related signaling pathways activation in MPNs.
\end{abstract}

\section{Introduction}

It has been generally accepted that chronic inflammation may increase the risk of cancer by providing bioactive molecules from the tumor microenvironment, including cytokines and growth factors that promote continuous cell proliferation and malignant transformation [1]. Interleukin-6 (IL-6) is a member of the IL-6-type cytokines family with pro- and antiinflammatory properties. They activate the Janus tyrosine kinase (JAK) family members (JAK1, JAK2, and TYK2), leading to the activation of transcription factors of the signal transducer and activator of transcription (STAT) family. All
IL-6-type cytokines potently activate STAT3 and to a minor extent STAT1, while SOCS3 is the primary inhibitor of IL6 signaling $[2,3]$. IL-6 is produced by a wide range of cells including monocytes/macrophages, $\mathrm{T}$ cells, endothelial cells, fibroblasts, and hepatocytes. IL- 6 regulates a variety of cell functions such as a cell proliferation, activation, and differentiation and has been proposed as a predictor of malignancy $[4,5]$.

IL-6 has been implicated as a critical activator of myelopoiesis in response to chronic inflammatory disorders, including myeloproliferative neoplasm (MPN) [6]. IL-6 levels are increased in primary myelofibrosis (PMF), with a positive 
correlation between IL- 6 and angiogenesis in bone marrow of MPN patients $[7,8]$. The endogenous levels of IL- 6 and soluble IL-6 receptor are also elevated in essential thrombocythemia (ET) [9]. It has been reported that although serum level of IL-6 is not increased in polycythemia vera (PV), the increased percentage of megakaryocytes secreting this cytokine is observed in bone marrow of patients with PV [10].

Activation of the JAK-STAT signaling pathway resulted in the production of IL-6 [11]. Moreover, JAK2-specific inhibition blocks STAT3 phosphorylation and IL-6 production in cancer cells [12]. STAT3 is predominantly activated by IL-6 receptor via JAK1/2 in cancer cell lines in association with transcriptional silencing of SOCS-1 by hypermethylation [13]. Moreover, JAK1/2 inhibition decreases a circulating level of proinflammatory cytokine IL-6 in MPN mouse model [14]. In a transgenic mouse model of Jak2V617F-mediated MPN, JAK2 inhibitor normalizes the pathologically high plasma concentrations of IL-6 [15]. Tumor necrosis factor-alpha (TNF- $\alpha$ ) stimulated IL-6 production is also suppressed by inhibition of JAK2 in multiple myeloma cells [16].

According to previous reports, proinflammatory cytokine IL-6 demonstrates JAK-STAT signaling dependence and has been augmented in MPNs. Majority of MPN patients have JAK2V617F mutation that constitutively stimulates JAKSTAT pathway. Using microarray analysis, we explore both JAK-STAT and IL- 6 signaling related genes in MPNs according to JAK2V617F mutant allele burden. IL-6 levels have been examined both in peripheral blood and bone marrow of patients with MPN. In addition, genes related to other major inflammatory pathways, such as transforming growth factorbeta (TGF- $\beta$ ) and nuclear factor-kappa B (NF- $\kappa \mathrm{B})$, have been evaluated in MPNs.

\section{Material and Methods}

2.1. Isolation of $\mathrm{CD}^{+} 4^{+}$Cells from the Peripheral Blood of MPN Patients. The study was approved by the Local Research Ethics Committee (Medical School, University of Belgrade). Informed consent was obtained from all patients included in the study. All study de novo patients were subject to $30 \mathrm{~mL}$ of peripheral blood draw on one occasion, collected in $10 \%$ sodium citrate. Each $30 \mathrm{~mL}$ of diluted peripheral blood $(1: 1.2$ with $\mathrm{Ca}^{2+} / \mathrm{Mg}^{2+}$-free phosphate buffer saline (PBS)) was layered gently on top of $15 \mathrm{~mL}$ lymphocyte separation medium (Capricorn Scientific GmbH, Ebsdorfergrund, Germany). After centrifugation $\left(400 \mathrm{~g}, 30 \mathrm{~min}, 20^{\circ} \mathrm{C}\right)$, the interface of containing mononuclear cells was collected and washed with PBS. The CD $34^{+}$cells were isolated from the collected mononuclear cells by magnetic separation column (Super Macs II, Miltenyi Biotec, Bergisch Gladbach, Germany) and mixture of magnetic microbeads conjugated with antibody against CD34 (Miltenyi Biotec) according to the manufacturer's instructions. The viable $\mathrm{CD} 34^{+}$cell counts were performed with the use of a trypan-blue exclusion technique (BioWhittaker). The high purity of recovered CD $34^{+}$cells was determined by flow cytometry using PE-anti-CD34 mAb (BD Biosciences, San Jose, CA, USA). Karyotype analysis did not show any chromosome aberrations in samples for microarray analysis.
2.2. Isolation of Total RNA. We used the RNeasy protocol for isolation of total RNA from $\mathrm{CD}_{3}{ }^{+}$cells according to the manufacturer's instructions (Qiagen $\mathrm{GmbH}$, Hilden, Germany). Concentration and integrity of total RNA were assessed using NanoDrop spectrophotometer (Thermo Fisher Scientific Inc., Wilmington, Delaware, USA) and Agilent 2100 Bioanalyzer Software (Agilent Technologies, Waldbronn, Germany) comparing the ratio of $28 \mathrm{~S}$ and $18 \mathrm{~S}$ RNA peaks to ensure that there is minimal degradation of the RNA sample.

2.3. DNA Sequencing. Genomic DNA was extracted from peripheral blood granulocytes of MPN patients by using the proteinase $\mathrm{K}$ and phenol-chloroform technique. Single nucleotide mutation of JAK2V617F gene was characterized by DNA sequencing after PCR amplification. PCR amplification was performed with wild-type JAK-2-specific forward primer $5^{\prime}$-tggcagagagaattttctgaact- $3^{\prime}$ and reverse primer $5^{\prime}$ ttcattgctttccttttcaca- $3^{\prime}$, confirmed by electrophoresis on an ethidium bromide-impregnated $1 \%$ agarose gel. PCR amplified samples were analyzed by sequencing on an automated ABI PRISM 3130 Genetic Analyzer (Applied Biosystems; Life Technologies, Carlsbad, CA, USA) with AB DNA Sequencing Analysis Software (v5.2) by using the Big Dye Terminator v3.1 Ready Reaction Cycle Sequencing Kit.

2.4. Immunohistochemical Analysis. Bone marrow tissue sections were fixed in 10\% neutral formalin solution for 24-36 hours and then decalcified in EDTA buffer for 3 hours and embedded in paraffin. The tissue sections were cut at $5 \mu \mathrm{m}$, heated at $56^{\circ} \mathrm{C}$ for $60 \mathrm{~min}$, and then deparaffinized and rehydrated through a series of xylenes and alcohols followed by an epitope retrieval step. Samples were treated with $3 \% \mathrm{H}_{2} \mathrm{O}_{2}$ solution in PBS to block endogenous peroxidase activity. The next step was incubation with anti-IL-6 antibody (Thermo Scientific, dilution $1: 400$ ) in a humidity chamber overnight at room temperature. Immunostaining was performed using the streptavidin-biotin technique (LSAB+/HRP Kit, DAKO). Immunoreactivity was visualized with DAKO Liquid DAB+ Substrate/Chromogen System counterstained with Mayer's hematoxylin (Merck, Whitehouse Station, NJ). For the negative control samples, normal serum and PBS buffer (1:500) were pipetted without primary antibodies. Immunoreactive cells were analyzed and scored at five powered fields in each sample using a computer-supported imaging system (analysis Pro 3.1) connected to the light microscope (Olympus AX70, Hamburg, Germany) with an objective magnification of $\times 40$. Immunohistochemical staining for IL-6 was performed in bone marrow of 34 subjects (10 PV: per 5 heterozygous and homozygous; 9 ET: 5 no mutation and 4 heterozygous, and 9 PMF: 5 no mutation, 4 heterozygous for JAK2V617F, and 6 healthy subjects).

2.5. ELISA Assay. Peripheral blood samples were obtained from 45 patients with newly diagnosed, untreated MPNs. The study included 14 PV, 14 ET, and 17 PMF cases. Patients were subclassified according to JAK2V617F mutational status as JAK2 homozygous, JAK2 heterozygous, and patients without mutation. We analyzed $7 \mathrm{PV}$ homozygous and $7 \mathrm{PV}$ 
heterozygous patients, 7 ET heterozygous and 7 ET patients without JAK2V617F mutation, and 3 PMF homozygous, 7 PMF heterozygous, and 7 PMF patients without JAK2V617F mutation. The control group comprised 7 healthy volunteers. Blood samples were collected with EDTA, and plasma was separated by centrifugation at $2000 \mathrm{rpm}$ per 15 minutes. The samples were stored at $-80^{\circ} \mathrm{C}$ until analysis. Plasma IL-6 level was measured using an ELISA kit (Thermo Scientific, Rockford, IL, USA), according to the manufacturer's instructions. All samples were tested in duplicate and data were expressed as average of IL-6 levels in $\mathrm{pg} / \mathrm{mL}$ for each group. Measurements were performed on an ELISA Multiscan Plus plate reader (Labsystems, Finland). Data were expressed as mean \pm standard error of the mean (SEM) of each group. They were analyzed by Student's $t$-test. A $p$ value $<0.05$ was chosen as the level of statistical significance.

2.6. Microarray Analysis. The human oligo probe set was purchased from Operon Human Genome Array-Ready Oligo Set Version 4.0 (Eurofins MWG Operon, Huntsville, AL, USA) which contains 35.035 oligonucleotide probes, representing approximately 25.100 unique genes. We have followed the MIAME (minimum information about a microarray experiment) guidelines for the data presentation. Also, our prior experience with primary cell cultures included quantitative PCR with housekeeping genes (S16 and HPRT) to establish similar efficiency of cDNA synthesis and PCR (data not shown). In microarray studies, for determination of gene expression in $\mathrm{CD}_{3} 4^{+}$cells of MPNs we used 8 healthy donors and $9 \mathrm{ET}$ ( 4 negative and 5 positive heterozygotes for JAK2V617F mutation), 7 PV (3 heterozygotes and 4 homozygotes for JAK2V617F), and 4 PMF ( 2 negative and 2 positive for $J A K 2 \mathrm{~V} 617 \mathrm{~F}$ ) patients. We isolated a low quantity of CD $34^{+}$ cells that correspond to low mRNA levels insufficient for microarray analysis, so we performed the amplification of total RNA using the Amino Allyl MessageAmp II aRNA Amplification kit (Life Technologies Corp., Carlsbad, CA, US), according to manufacturer instruction. We used $0.3 \mu \mathrm{g}$ of total RNA from MPN patients for amplification. For microarray analyses we used $3 \mu \mathrm{g}$ of amplified RNA. Total human universal RNA (HuURNA), isolated from a collection of adult human tissues to represent a broad range of expressed genes from both male and female donors (BD Biosciences, Palo Alto, CA), served as a universal reference control in the competitive hybridization. All examined MPN samples were hybridized against HuURNA. For hybridization, the hybridization mixture of cDNA probe and aRNA was preheated at $100^{\circ} \mathrm{C}$ for 2 minutes and centrifuged for 1 minute at $10.000 \mathrm{rpm} .20 \mu \mathrm{L}$ of preheated $\left(42^{\circ} \mathrm{C}\right)$ Ambion hybridization buffer (20x SSC in 10\% SDS) was mixed with hybridization mixture. Total volume of the hybridization mixture was added on the array in slide and covered with cover slip. Slides were placed in MAUI hybridization chamber (BioMicro Systems, Inc., Salt Lake City, UT, USA) and incubated overnight at $42^{\circ} \mathrm{C}$. Slides were then washed for 4 minutes each in 1x SSC and 0.1x SSC and spin-dried. Microarray slides were scanned in both Cy3 $(532 \mathrm{~nm})$ and Cy5 (635 nm) channels using Axon GenePix 4000B scanner (Axon Instruments, Inc., Foster City, CA) with a 10-micron resolution. Scanned microarray images were exported as TIFF files to GenePix Pro 3.0 software for image analysis. The average of the total $\mathrm{Cy} 3$ and $\mathrm{Cy} 5$ signal gave a ratio that was used to normalize the signals. Each microarray experiment was globally normalized to make the median value of the $\log _{2}$-ratio equal to zero. For advanced data analysis, gpr and jpeg files were imported into microarray database and normalized by software tools provided by NIH Center for Information Technology (http://nciarray.nci.nih.gov/). Spots with confidence interval of 99 ( $\geq 2$ fold) with at least 150-fluorescence intensity for both channel and $30 \mu \mathrm{m}$ spot size were considered good quality spots for analysis. The microarray data were available from Gene Expression Omnibus (http://www.ncbi.nlm.nih.gov/geo; accession number GSE55976).

2.7. Statistical Analysis. For microarray data management and analysis, we used NCI/CIT microarray database (mAdb) system. The one-way ANOVA was applied using mAdb software for measurement of statistical significance in gene expression among MPNs. For mAdb hierarchical clustering we used uncentered correlation that applied a modified Pearson correlation equation which assumes that the means are 0.

\section{Results}

3.1. Analysis of Peripheral Blood Cells in MPN Patients according to JAK2V617F Mutant Allele Burden. We examined the levels of peripheral blood cells from MPN patients in correlation to JAK2V617F mutant allele burden. We observed 63 patients with ET, 92 patients with PV, 50 patients with PMF, 12 healthy subjects, and 10 patients with secondary erythrocytosis. Level of thrombocytes was reduced, while erythrocyte and hemoglobin levels were elevated in ET patients heterozygous for JAK2V617F mutation versus ET patients without JAK mutation (Table 1). PV patients heterozygous and homozygous for JAK2V617F mutation had significantly increased levels of $\mathrm{CD} 34^{+}$cells, leukocytes, thrombocytes, and erythrocytes but reduced MCV compared to secondary erythrocytosis. $\mathrm{CD} 34^{+}$cells were generally increased in peripheral blood of PMF patients, particularly in JAK2V617F mutation positive patients. The average number of $\mathrm{CD} 34^{+}$ cells (cells $\mu \mathrm{L}$ ) in peripheral blood was approximately 6 in PV and ET and 111 in PMF group, increased in comparison to mean value for healthy subjects $(2.75 \pm 1$ cells $/ \mu \mathrm{L})$. In addition, leukocytes and erythrocytes were increased both in heterozygous and homozygous JAK2V617F mutated forms comparing to PMF patients without mutation. We observed lower thrombocyte levels and MCV in homozygous PMF patients, while hemoglobin levels were significantly increased in heterozygous PMF patients compared to JAK2V617F unmutated PMF patients (Table 1).

\subsection{Microarray Analysis of Total Gene Expression in $C D 34^{+}$} Cells of MPNs according to JAK2V617F Mutant Allele Burden. Using microarray analysis, the total gene expression has been examined separately in $\mathrm{CD}_{3} 4^{+}$cells of $\mathrm{PV}, \mathrm{ET}$, and 
TABLE 1: Blood test results of examined MPN patients according to JAK2 mutant allele burden.

\begin{tabular}{|c|c|c|c|c|c|c|c|}
\hline MPN & $\begin{array}{l}J A K 2 \\
\text { V617P } \\
\end{array}$ & $\begin{array}{c}\mathrm{CD}^{+} 4^{+} \\
(\text {cells } / \mu \mathrm{L})\end{array}$ & $\begin{array}{l}\text { Leukocytes } \\
\left(\times 10^{9} / \mathrm{L}\right)\end{array}$ & $\begin{array}{l}\text { Thrombocytes } \\
\left(\times 10^{9} / \mathrm{L}\right)\end{array}$ & $\begin{array}{l}\text { Erythrocytes } \\
\left(\times 10^{12} / \mathrm{L}\right)\end{array}$ & $\mathrm{MCV}$ & $\begin{array}{c}\text { Hemoglobin } \\
(\mathrm{g} / \mathrm{L})\end{array}$ \\
\hline \multirow{2}{*}{ ET } & 0 & $6.3( \pm 3.4)$ & $8.77( \pm 2.4)$ & $1110( \pm 358)$ & $4.6( \pm 0.4)$ & $88.7( \pm 3.7)$ & $134.1( \pm 14)$ \\
\hline & $<50 \%$ & $6.2( \pm 6.1)$ & $9.1( \pm 3.5)$ & $815( \pm 249)^{2}$ & $5( \pm 0.53)^{2}$ & $87( \pm 3.9)$ & $142( \pm 13)^{1}$ \\
\hline \multirow{3}{*}{ PV } & Sec Er & $2.5( \pm 0.7)$ & $7.25( \pm 1.9)$ & $203( \pm 46)$ & $5.34( \pm 0.4)$ & $89.8( \pm 3.6)$ & $161.6( \pm 13)$ \\
\hline & $<50 \%$ & $6.3( \pm 4.6)^{1}$ & $12.2( \pm 3.9)^{2}$ & $807( \pm 349)^{2}$ & $6.1( \pm 0.8)^{2}$ & $82( \pm 8.8)^{2}$ & $158.4( \pm 15)$ \\
\hline & $>50 \%$ & $9.4( \pm 8.2)^{1}$ & $17.3( \pm 9.5)^{2}$ & $631( \pm 270)^{2}$ & $6.5( \pm 0.9)^{2}$ & $74.6( \pm 8.8)^{2}$ & $152.4( \pm 17)$ \\
\hline \multirow{3}{*}{ PMF } & 0 & $29.8( \pm 37)$ & $8.8( \pm 3.1)$ & $905( \pm 320)$ & $4.4( \pm 0.44)$ & $87.1( \pm 5.6)$ & $126.5( \pm 17)$ \\
\hline & $<50 \%$ & $99( \pm 212)$ & $12.9( \pm 5.1)^{2}$ & $804( \pm 364)$ & $4.9( \pm 0.8)^{1}$ & $84( \pm 6.2)$ & $138( \pm 14)^{1}$ \\
\hline & $>50 \%$ & $126( \pm 158)$ & $14.2( \pm 5.5)^{2}$ & $509( \pm 331)^{2}$ & $5.34( \pm 1.3)^{2}$ & $77.7( \pm 11)^{2}$ & $129.1( \pm 20)$ \\
\hline
\end{tabular}

$t$-test: ${ }^{1} p<0.05,{ }^{2} p<0.01$ versus MPNs without JAK2 mutation (0) and secondary erythrocytosis (Sec Er).

PMF groups. A distribution of total gene expression of MPN $\mathrm{CD} 34^{+}$cells has been presented in comparison to controls and according to JAK2V617F mutant allele burden (Figure 1). The quantity of shared genes in $\mathrm{CD} 34^{+}$cells was presented by Venn diagram in JAK2V617F heterozygous, homozygous, and mutation-free forms (Figure 1). Moreover, the statistical analyses of total gene expression have been performed in $\mathrm{PV}, \mathrm{ET}$, and PMF according to JAK2V617F mutant allele burden (see Supplemental Table 1 in Supplementary Material available online at http://dx.doi.org/10.1155/2015/453020). We observed 261 significantly changed genes $(p<0.01)$ in PV, 82 significant genes $(p<0.01)$ in ET, and 94 genes $(p<$ 0.05 ) in PMF comparing to controls and sporadically among MPNs (Supplemental Table 1). ET and PMF shared 43\% and $26 \%$ of their significantly changed genes with PV, respectively. CHMP5 gene expression was generally increased in MPNs and further on augmented by $J A K 2 \mathrm{~V} 617 \mathrm{~F}$ allele burden. SOD2 gene expression was also generally increased in MPNs but only in PV augmented by JAK2V617F allele burden. WAC gene expression was generally increased in PV, ET, and heterozygous PMF patients. CCND3, HN1, and LOC124685 were only significantly upregulated genes simultaneously in ET and PMF compared to control subjects (Supplemental Table 1).

3.3. JAK-STAT Signaling Pathway Related Genes in $C D 34^{+}$ Cells of MPNs. The examination of JAK2V617F mutant allele burden influence has been expanded toward JAKSTAT signaling pathway in CD $34^{+}$cells of MPNs. According to Table 2, several genes involved in JAK-STAT signaling have been modified by JAK2V617F allele burden. Colony stimulating factor 3 receptor (CSF3R) has been significantly increased in JAK2V617F positive ET and PV patients. The vakt murine thymoma viral oncogene homolog 2 (AKT2) has been significantly increased in JAK2V617F homozygous PV and JAK2V617F positive PMF patients. Cyclin D3 (CCND3) has been generally augmented in MPNs not influenced by JAK2V617F mutation. Pim-1 oncogene (PIM1) has been also generally augmented in MPNs but reached statistical significance only in PV, similar to protein tyrosine phosphatase, nonreceptor type 11 (PTPN11). However, PTPN6 has been significantly increased only in $J A K 2 \mathrm{~V} 617 \mathrm{~F}$ heterozygous ET patients. STAT1 and STAT2 gene expression have been increased in heterozygous ET and PV patients, while STAT3 only in homozygous PV patients. STAT5A has been significantly decreased in ET and PMF with no JAK2V617F mutation as well as in homozygous PV patients (Table 2). In addition, these JAK-STAT signaling related genes were also shown in hierarchical clustering analysis to illustrate their associations (Figure 2). The genes only and steadily expressed in homozygous PV were GRB2, IL15, LEPR, and PIK3CA (Table 2).

3.4. IL-6 and Inflammatory Signaling Pathways Related Gene Expression in CD $34^{+}$Cells of MPNs. Regarding IL-6 signaling pathway related genes several of them were already presented in Table 2, such as PTPN11, STAT3, JAK1, JAK2, interleukin 6 signal transducer (IL6ST), and growth factor receptor-bound protein 2 (GRB2). IL6ST has been increased in CD34 ${ }^{+}$cells of JAK2V617F mutation positive ET and PV patients (Table 2). $M A P 2 K 1$ was significantly increased in $\mathrm{CD} 34^{+}$cells of PV (Table 3). RAF1 and FOS gene expression were increased in ET and PV but do not reach statistical significance compared to controls (Table 3 ). Other proinflammatory pathways such as NF- $\kappa \mathrm{B}$ and TGF- $\beta$ signaling demonstrated elevation of TNFRSF1A and TRADD genes expression in $\mathrm{CD}_{3} 4^{+}$cells of $\mathrm{PMF}$ and $\mathrm{PV}$, respectively, as well as decrease of CDKN2B and increase of TFDP1 genes in PMF (Table 3). Antiinflammatory IL-10 signaling pathway related genes $B L V R A$ and $H M O X 1$ demonstrated increased expression in $\mathrm{CD}_{3} 4^{+}$ cells of PV and ET, respectively (Table 3 ).

3.5. IL-6 Protein Levels in MPNs according to JAK2V617F Mutant Allele Burden. We examined IL-6 protein levels in peripheral blood (plasma) and bone marrow of MPNs in accordance with JAK2V617F mutant allele burden. IL-6 protein levels were generally increased in plasma of MPNs reaching statistical significance in majority of patients, not influenced by JAK2V617F mutant allele burden (Figure 3(a)). Furthermore, there is a positive correlation between IL-6 protein levels and erythrocytes $(r=0.933, p<0.01)$, hemoglobin $(r=0.733, p<0.05)$, and hematocrit $(r=0.818$, $p<0.05)$ levels in PV patients heterozygous for JAK2V617F mutation. IL-6 protein levels were also commonly and significantly increased in bone marrow stromal cells of 


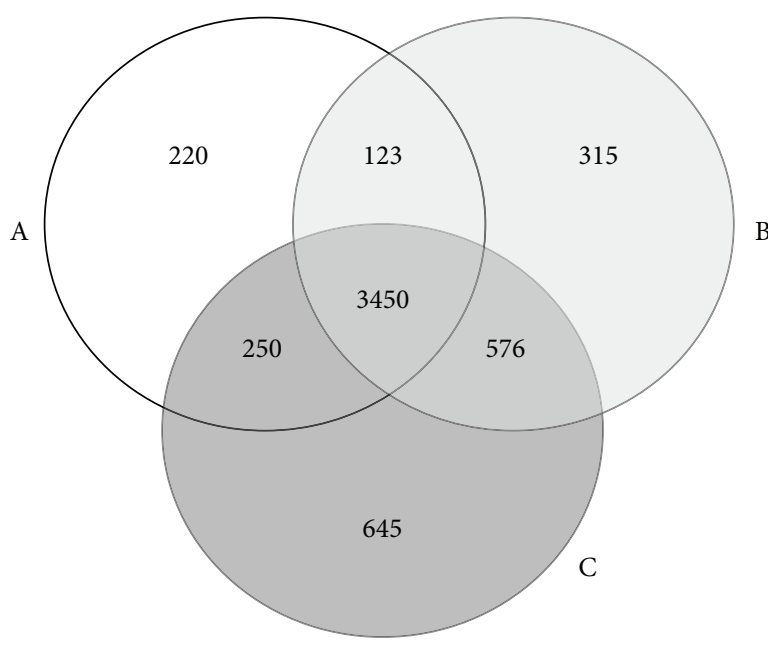

ET

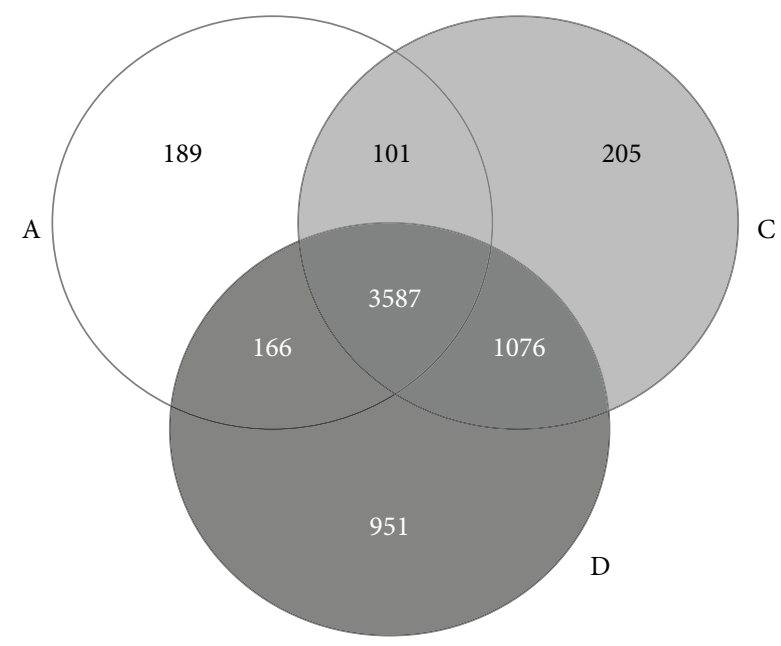

PV

\section{CD $34^{+}$ \\ A: Control \\ B: No mutation

\begin{abstract}
C: Heterozygote
D: Homozygote
\end{abstract}

(a)

\section{$\mathrm{CD} 34^{+}$}
A: Control
C: Heterozygote
B: No mutation
D: Homozygote

(b)

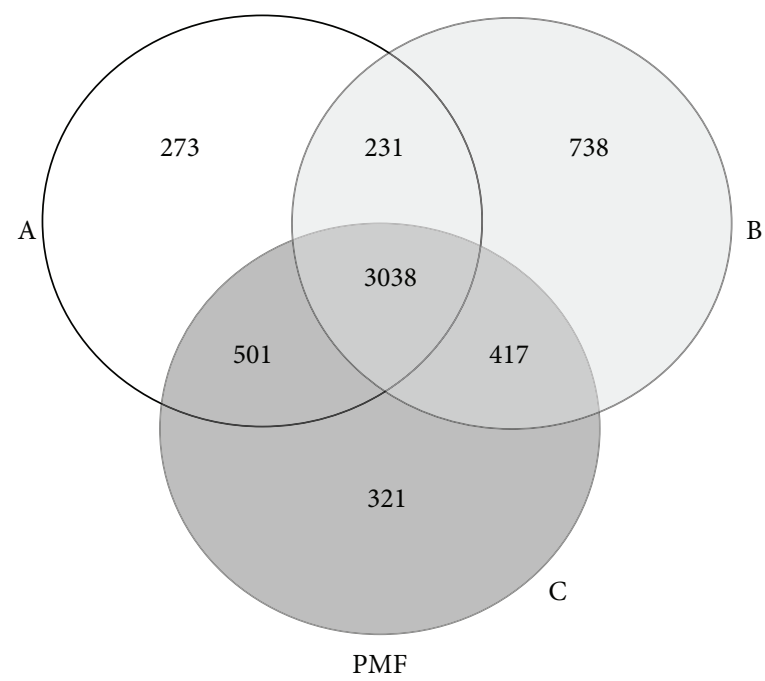

CD $34^{+}$

A: Control $\quad$ C: Heterozygote

B: No mutation D: Homozygote

(c)

FIGURE 1: Microarray study of gene expression in CD34 ${ }^{+}$cells from peripheral blood of MPN patients. The Venn diagram shows similarity of total gene expression in controls $(n=8)$ and (a) JAK2V617F heterozygous and no mutation ET forms $(n=9)$, (b) JAK2V617F heterozygous and homozygous PV forms $(n=7)$, and (c) JAK2V617F heterozygous and no mutation PMF forms $(n=4)$.

MPNs (Figure 3(b)). This bone marrow augmentation of IL6 expression was more prominent in JAK2V617F positive ET and PMF patients $(p<0.01$, Figure $3(\mathrm{~b}))$.

\section{Discussion}

Presence of $J A K 2$ V617F mutation correlated with a reduced level of thrombocytosis in ET and increased absolute number of circulating $\mathrm{CD} 34^{+}$cells, leukocytosis, and erythrocytosis in patients with PV. In addition, increased JAK2V617F allele burden augmented leukocytosis and erythrocytosis but reduced thrombocytosis and MCV in patients with PMF. Using Venn diagram, a distribution of gene expression has been presented, with a list of significantly modified genes in CD34 $4^{+}$cells of MPNs, compared to controls and according to JAK2V617F mutant allele burden. 261 significantly changed 
TABLE 2: Statistically significant genes related to JAK-STAT pathway in CD34 ${ }^{+}$cells of MPNs according to JAK2V617F mutant allele burden.

\begin{tabular}{|c|c|c|c|c|c|c|c|}
\hline \multirow[b]{2}{*}{ JAK2 } & \multirow{2}{*}{$\begin{array}{c}\text { Control } \\
-\end{array}$} & \multicolumn{2}{|c|}{$\mathrm{ET}$} & \multicolumn{2}{|c|}{ PV } & \multicolumn{2}{|c|}{ PMF } \\
\hline & & - & + & Hetero & Homo & - & + \\
\hline Genes & $\mathrm{AV} \pm \mathrm{SD}$ & $\mathrm{AV} \pm \mathrm{SD}$ & $\mathrm{AV} \pm \mathrm{SD}$ & $\mathrm{AV} \pm \mathrm{SD}$ & $\mathrm{AV} \pm \mathrm{SD}$ & $\mathrm{AV} \pm \mathrm{SD}$ & $\mathrm{AV} \pm \mathrm{SD}$ \\
\hline AKT2 & $0.94 \pm 0.18$ & $1.11 \pm 0.58$ & $0.80 \pm 0.40$ & $0.66 \pm 0.37$ & $1.3 \pm 0.1^{* *}$ & $0.7 \pm 0.30$ & $1.1 \pm 0.17^{*}$ \\
\hline CSF3R & $2.83 \pm 0.20$ & $2.99 \pm 0.37$ & $3.8 \pm 0.6^{* *}$ & $3.2 \pm 0.6^{*}$ & $3.2 \pm 0.2^{* *}$ & $2.92 \pm 1.01$ & $3.20 \pm 0.50$ \\
\hline CBL & $0.49 \pm 0.45$ & $-0.1 \pm 0.3^{*}$ & $0.28 \pm 0.65$ & $0.29 \pm 0.06$ & $0.61 \pm 0.14$ & $0.16 \pm 0.85$ & $0.79 \pm 0.13$ \\
\hline CCND2 & $0.30 \pm 0.55$ & $0.01 \pm 0.05$ & $-0.38 \pm 0.6$ & $0.56 \pm 0.39$ & $0.38 \pm 0.38$ & $0.02 \pm 0.20$ & $0.33 \pm 0.86$ \\
\hline CCND3 & $0.21 \pm 0.22$ & $1.1 \pm 0.5^{* *}$ & $0.9 \pm 0.4^{* *}$ & $0.66 \pm 0.57$ & $0.9 \pm 0.3^{* *}$ & $1.2 \pm 0.4^{* *}$ & $0.76 \pm 0.2^{*}$ \\
\hline CNTFR & $0.52 \pm 0.99$ & $0.65 \pm 0.83$ & $0.97 \pm 0.71$ & $0.25 \pm 0.47$ & $-1.03 \pm 0.2$ & -1.2 & $-0.64 \pm 1.3$ \\
\hline CREBBP & $0.23 \pm 0.60$ & $-0.35 \pm 0.3$ & $0.35 \pm 0.34$ & $0.45 \pm 0.44$ & $0.10 \pm 0.51$ & $-0.41 \pm 0.6$ & $0.05 \pm 0.58$ \\
\hline GRB2 & 1.65 & & 2.05 & & $1.91 \pm 0.12$ & 1.48 & \\
\hline IFNAR2 & $0.51 \pm 1.13$ & $1.41 \pm 0.46$ & $1.76 \pm 0.49$ & $1.38 \pm 0.25$ & $1.32 \pm 0.38$ & $1.23 \pm 0.69$ & 0.83 \\
\hline IFNGR1 & $0.77 \pm 0.22$ & 0.92 & $1.14 \pm 0.28$ & $0.85 \pm 0.12$ & $1.18 \pm 0.40$ & 1.88 & \\
\hline IFNGR2 & $0.77 \pm 0.13$ & 2.06 & $1.58 \pm 0.60$ & $1.94 \pm 0.48$ & $2.0 \pm 0.1^{* *}$ & 1.96 & 1.87 \\
\hline IL10RB & $0.96 \pm 0.28$ & $0.88 \pm 0.55$ & $1.52 \pm 0.60$ & $1.23 \pm 0.49$ & $0.99 \pm 0.79$ & $0.86 \pm 1.01$ & $0.80 \pm 0.05$ \\
\hline IL11RA & $1.69 \pm 0.13$ & 0.31 & 1.87 & $1.66 \pm 0.15$ & $1.92 \pm 0.39$ & 1.49 & \\
\hline IL15 & & & 1.1 & 2.14 & $2.24 \pm 0.04$ & & \\
\hline IL15RA & $0.76 \pm 0.47$ & $0.19 \pm 0.09$ & $0.50 \pm 0.34$ & $0.27 \pm 0.19$ & $0.41 \pm 0.07$ & $0.16 \pm 0.32$ & $0.60 \pm 0.39$ \\
\hline IL23A & $-1.18 \pm 0.2$ & $-0.7 \pm 0.4^{*}$ & $-1.11 \pm 0.4$ & $-0.75 \pm 0.4$ & $-0.5 \pm 0.4^{*}$ & $-1.3 \pm 0.2^{*}$ & $-1.7 \pm 0.02^{* *}$ \\
\hline IL6ST & $-1.10 \pm 0.2$ & $-0.46 \pm 0.4$ & $0.1 \pm 0.6^{* *}$ & $0.06 \pm 0.4^{*}$ & $-0.1 \pm 0.6^{*}$ & $-0.92 \pm 0.7$ & -0.84 \\
\hline JAK1 & $0.88 \pm 0.24$ & 1.2 & 0.93 & $1.42 \pm 0.03$ & $1.7 \pm 0.1^{* *}$ & 1.47 & 1.11 \\
\hline JAK2 & 2.25 & & $3.54 \pm 0.81$ & $4.07 \pm 0.27$ & $3.96 \pm 0.57$ & & 3.01 \\
\hline LEPR & 0.18 & 0.92 & 0.77 & 0.81 & $0.39 \pm 0.21$ & 1.13 & 1.07 \\
\hline MYC & $-1.86 \pm 0.3$ & $-2.28 \pm 0.2$ & $-1.70 \pm 0.4$ & $-1.27 \pm 0.7$ & $-1.58 \pm 0.5$ & $-1.70 \pm 1.1$ & -0.79 \\
\hline PIAS1 & $0.48 \pm 0.38$ & $0.04 \pm 0.49$ & $1.10 \pm 0.61$ & $1.04 \pm 0.37$ & $0.97 \pm 0.12$ & $0.21 \pm 0.69$ & $0.61 \pm 0.05$ \\
\hline PIAS4 & $1.88 \pm 0.43$ & $2.05 \pm 0.20$ & $2.24 \pm 0.77$ & $1.86 \pm 0.42$ & $1.84 \pm 0.12$ & $1.89 \pm 0.12$ & $2.06 \pm 0.51$ \\
\hline PIK3CA & & & 1.45 & 1.51 & $1.64 \pm 0.13$ & & \\
\hline PIK3R1 & 0.72 & 1.04 & 2.41 & $2.45 \pm 0.68$ & 1.95 & 2.21 & \\
\hline PIM1 & $0.28 \pm 0.2$ & $0.90 \pm 0.19$ & $1.10 \pm 0.48$ & $1.37 \pm 0.4^{*}$ & $1.42 \pm 0.4^{*}$ & $1.03 \pm 0.38$ & $0.82 \pm 0.28$ \\
\hline PTPN11 & $0.78 \pm 0.53$ & $1.10 \pm 0.46$ & $0.84 \pm 0.38$ & $1.09 \pm 0.43$ & $1.03 \pm 0.4^{*}$ & 0.91 & $0.44 \pm 0.16$ \\
\hline PTPN6 & $0.44 \pm 0.43$ & $0.70 \pm 0.18$ & $1.35 \pm 0.4^{*}$ & $1.12 \pm 0.60$ & $0.41 \pm 0.19$ & $0.05 \pm 0.23$ & 0.47 \\
\hline SOCS2 & $1.48 \pm 0.61$ & $1.12 \pm 0.94$ & $1.21 \pm 0.87$ & $1.71 \pm 0.73$ & $1.75 \pm 1.09$ & $2.06 \pm 0.04$ & $2.20 \pm 0.90$ \\
\hline SPRED2 & $0.17 \pm 0.34$ & $-0.45 \pm 0.2$ & -0.58 & & & -0.82 & -0.73 \\
\hline SPRY4 & $-0.13 \pm 0.7$ & $-0.14 \pm 0.7$ & $-0.35 \pm 0.2$ & $-0.61 \pm 0.2$ & $-1.14 \pm 0.2$ & -1.03 & $-1.00 \pm 0.7$ \\
\hline STAT1 & $3.60 \pm 0.55$ & $3.37 \pm 0.80$ & $4.68 \pm 0.8^{*}$ & $4.4 \pm 0.05^{*}$ & $5.1 \pm 0.5^{* *}$ & $3.31 \pm 1.44$ & $4.18 \pm 0.39$ \\
\hline STAT2 & $1.45 \pm 0.51$ & $1.57 \pm 0.38$ & $2.39 \pm 0.6^{*}$ & $2.25 \pm 0.2^{*}$ & $2.01 \pm 0.42$ & $1.58 \pm 0.74$ & $1.75 \pm 0.35$ \\
\hline STAT3 & $1.13 \pm 0.26$ & $1.54 \pm 0.07$ & $1.32 \pm 0.30$ & $1.05 \pm 0.81$ & $1.8 \pm 0.3^{* *}$ & $1.59 \pm 0.13$ & $1.62 \pm 0.57$ \\
\hline STAT5A & $1.39 \pm 0.25$ & $0.8 \pm 0.01^{*}$ & $0.90 \pm 0.53$ & $0.99 \pm 0.43$ & $1.01 \pm 0.2^{*}$ & $0.5 \pm 0.2^{* *}$ & 1.93 \\
\hline TYK2 & $0.36 \pm 0.28$ & 0.63 & $0.85 \pm 0.43$ & $0.75 \pm 0.33$ & $0.35 \pm 0.32$ & 0.58 & \\
\hline
\end{tabular}

${ }^{*} p<0.05,{ }^{* *} p<0.01$, and gene expression in MPNs versus control.

genes in PV have been observed, 82 in ET, and 94 genes in PMF. We demonstrated that majority of JAK-STAT signaling pathway related genes have been augmented in MPNs with increased JAK2V617F allele burden, except STAT5 gene. Proinflammatory IL-6 (IL6ST, PTPN11), NF- $\kappa$ B (TNFRSF1A, TRADD), and TGF- $\beta$ (TFDP1) signaling pathways demonstrated increase of the related genes, as well as certain antiinflammatory IL-10 signaling pathway related genes (BLVRA, $H M O X 1)$ in $\mathrm{CD}_{3} 4^{+}$cells of MPNs. IL- 6 cytokine levels were increased in plasma of MPNs, as well as IL-6 protein levels in bone marrow stroma of MPNs, where they demonstrated dependence of JAK2V617F presence in ET and PMF patients.

According to a large study with $1545 \mathrm{PV}$ patients, median hemoglobin level was $184 \mathrm{~g} / \mathrm{L}$ (in range 151-265), median leukocyte count was $10.4 \times 10^{9} / \mathrm{L}$ (in range $3-171$ ), and median platelet count was $466 \times 10^{9} / \mathrm{L}$ (in range $7-2370$ ). Leukocytosis was present in $49 \%$, while thrombocytosis in $53 \%$ of PV patients [20]. In other study with $327 \mathrm{PV}$ patients, median hemoglobin level was $176 \mathrm{~g} / \mathrm{L}$, median leukocyte count was $13 \times 10^{9} / \mathrm{L}$, and median platelet count was $515 \times 10^{9} / \mathrm{L}[21]$. In study with 707 PMF patients, median hemoglobin level 

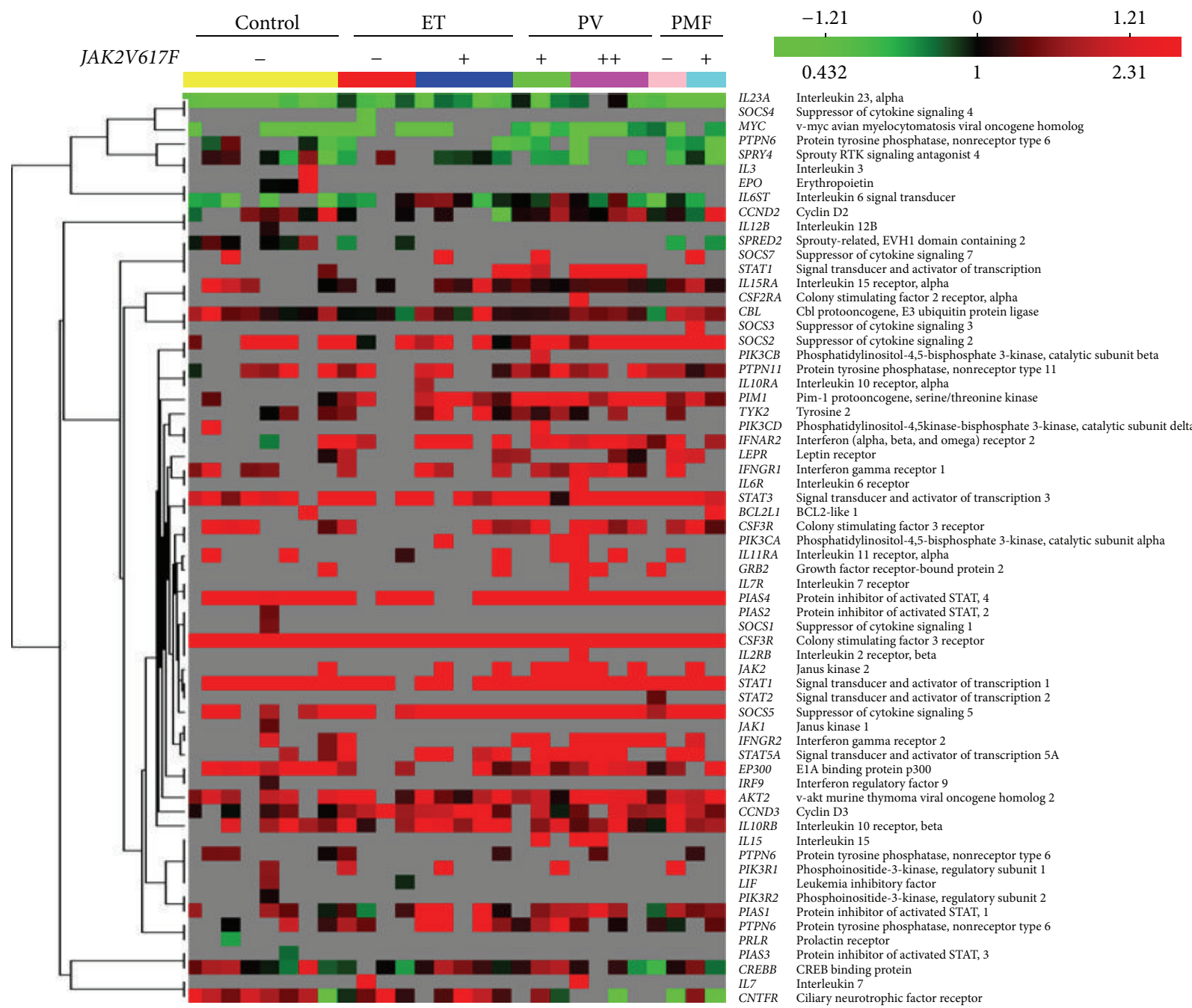

FIGURE 2: Hierarchical clustering of JAK-STAT signaling pathway related genes expressed in CD34 ${ }^{+}$cells of MPNs. The color indicates the relative fold expression of each gene: red indicates increased expression, green negative expression, and black not changed expression, while gray stands for absent expression per each examined sample. The gene correlations are uncentered.

was $110 \mathrm{~g} / \mathrm{L}$ (in range 63-149), median leukocyte count was $13 \times 10^{9} / \mathrm{L}$ (in range $2.7-35.0$ ), and median platelet count was $515 \times 10^{9} / \mathrm{L}$ (in range 44-990) [22]. In next study with 612 MPN patients, mean hemoglobin level was 137, 174, and $119 \mathrm{~g} / \mathrm{L}$, mean leukocyte count was $10.2,12.4$, and $13.3 \times 10^{9} / \mathrm{L}$, and mean platelet count was 889,579 , and $517 \times 10^{9} / \mathrm{L}$ for ET, PV, and PMF patients, respectively [23]. According to a small study with $21 \mathrm{ET}$ patients, median red cell level was 4.46 $\times 10^{12} / \mathrm{L}(3.14-5.78)$, median hemoglobin level was $135 \mathrm{~g} / \mathrm{L}$ (105-166), median leukocyte count was $10.7 \times 10^{9} / \mathrm{L}(5.1-$ $19.8)$, and median platelet count was $872 \times 10^{9} / \mathrm{L}(310-1443)$. In the same report with $17 \mathrm{PV}$ patients, median red cell level was $6.15 \times 10^{12} / \mathrm{L}(5.09-7.95)$, median hemoglobin level was $165 \mathrm{~g} / \mathrm{L}$ (138-205), median leukocyte count was $10.0 \times$ $10^{9} / \mathrm{L}(6.6-27.2)$, and median platelet count was $501 \times 10^{9} / \mathrm{L}$ (221-936) [24]. Reported laboratory findings are in range of our presented results. In our study, hemoglobin mean level $158 \mathrm{~g} / \mathrm{L}$ for PV was reduced, $142 \mathrm{~g} / \mathrm{L}$ for ET was similar, $138 \mathrm{~g} / \mathrm{L}$ for PMF was increased in comparison to other studies but is still in range of the observed results [20, 21, 24]. The levels of red blood cells and leukocytes in our MPN patients were similar to previous reports. The level of platelets in our ET patients was similar but elevated in PV and PMF patients in comparison to previous results. However, the increased values were within the limit of the reported results.

Median numbers and ranges of circulating $\mathrm{CD} 34^{+}$cells were $2.3 \times 10^{6} / \mathrm{L}(0-5)$ in control subjects, $2.2 \times 10^{6} / \mathrm{L}(0-14)$ in those with PV, $2.4 \times 10^{6} / \mathrm{L}(0-14)$ in those with ET, and $114 \times 10^{6} / \mathrm{L}(6-2520)$ in PMF patients [25]. Comparing to our study, CD $34^{+}$cell levels were reduced in ET and PV patients but were still within range, while they were similar for PMF patients (Table 1). More similar median levels of circulating CD $34^{+}$cells in PV and ET have been observed in another study: $8.9 \times 10^{6} / \mathrm{L}(0-31)$ in those with PV, $4.1 \times 10^{6} / \mathrm{L}(0-18)$ in those with ET, and $60 \times 10^{6} / \mathrm{L}$ (11-449) in PMF patients [17]. A significant and positive correlation between the proportion 


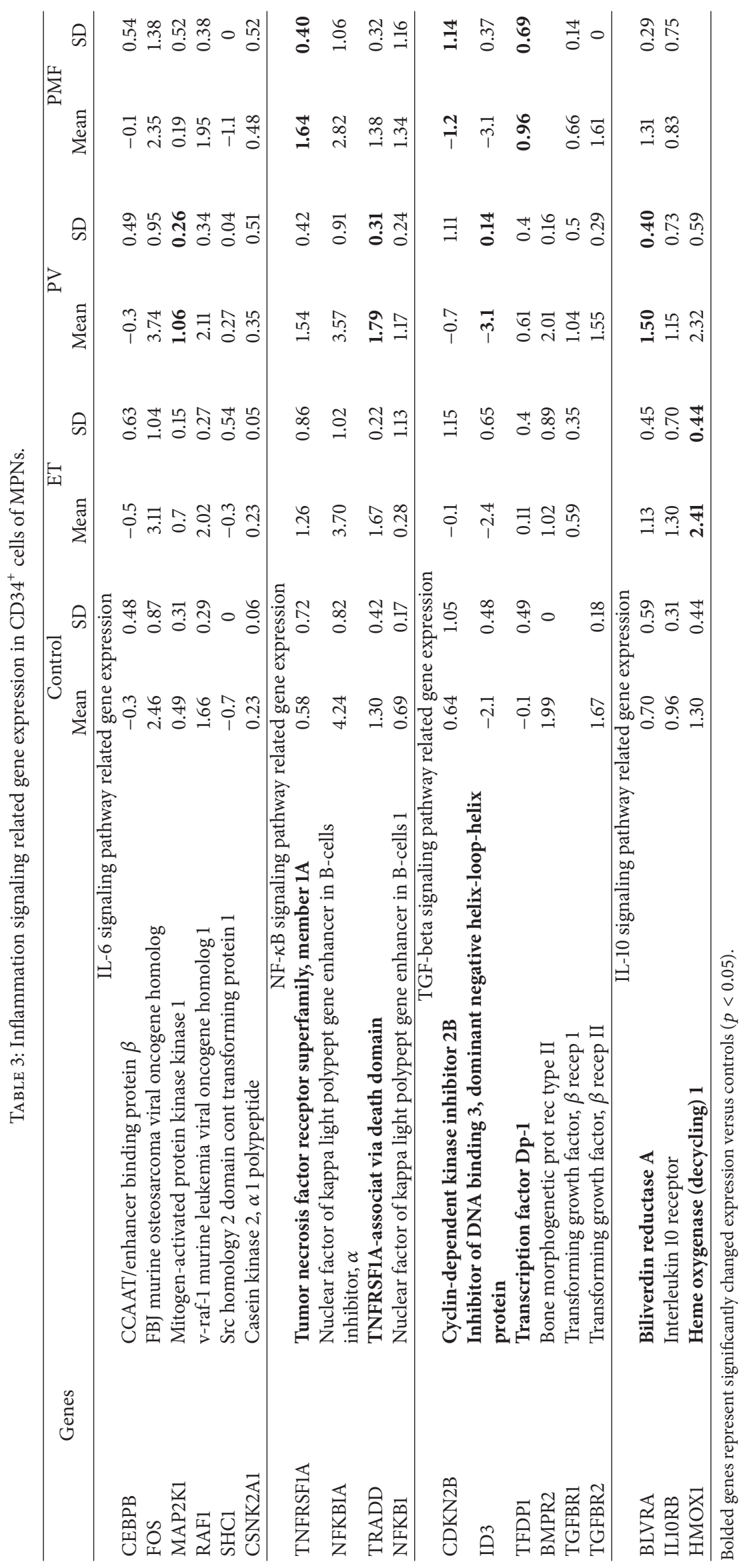



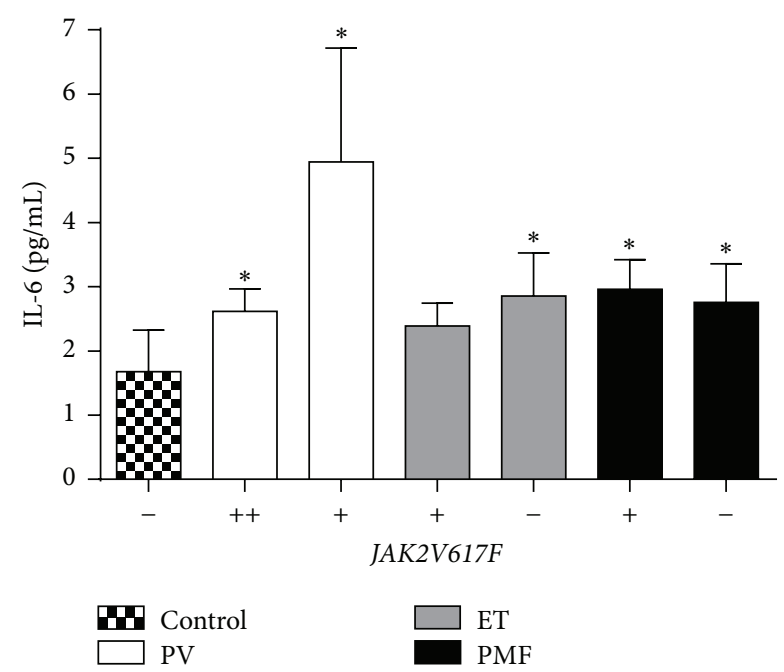

(a) Peripheral blood

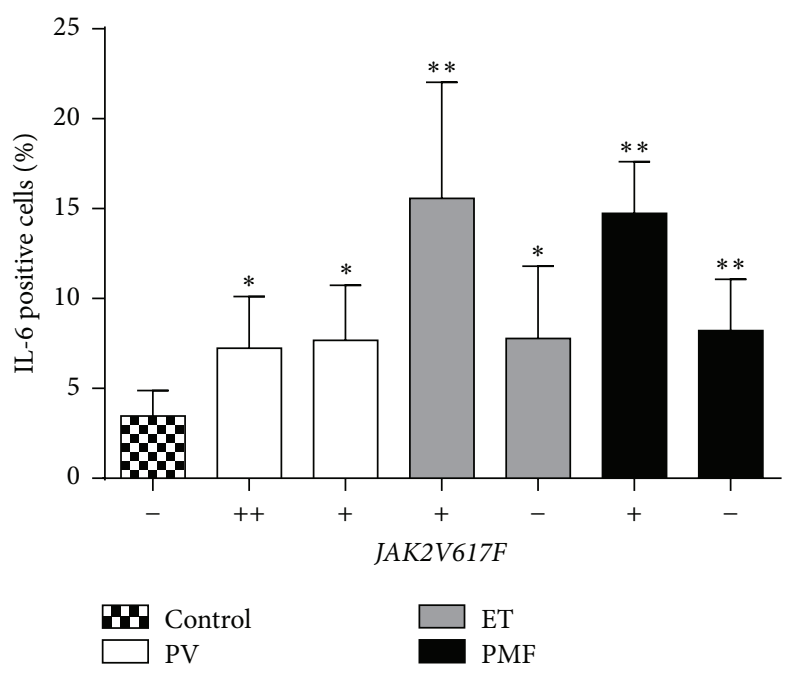

(b) Bone marrow

FIGURE 3: IL-6 levels in peripheral blood and bone marrow of MPNs in accordance with JAK2V617F mutant allele burden. (a) IL-6 level in peripheral blood of patients with MPN determined by ELISA $(n=7)$. (b) IL- 6 level in bone marrow of patients with MPN determined by immunohistochemistry. (-) no JAK2V617F, (+) heterozygosity, and (++) homozygosity for JAK2V617F mutation $(n=4-5$, plus control $n=6)$. Values are mean \pm SEM. ${ }^{*} p<0.05,{ }^{* *} p<0.01$ regarding MPNs versus Control.

of JAK2V716F mutant alleles and circulating $\mathrm{CD} 34^{+}$counts in MPNs has been found. CD $34^{+}$cell counts were similar in healthy subjects (median value $1.3 \times 10^{6} / \mathrm{L}$ ) and individuals with secondary erythrocytosis (median value $1.8 \times 10^{6} / \mathrm{L}$ ). However, PV patients with JAK2V617F had higher circulating $\mathrm{CD} 34^{+}$counts than healthy individuals without the mutation [26]. This is in accordance with our observation. PV patients carrying up to $50 \%$ JAK2 mutant alleles had slightly but significantly higher $\mathrm{CD} 34^{+}$cell counts (median value $3.2 \times$ $10^{6} / \mathrm{L}$ ) than controls, doubled in our results. Moreover, patients with PV and more than 50\% JAK2V617F allele had markedly higher $\mathrm{CD} 34^{+}$cell counts (median value $21.4 \times$ $10^{6} / \mathrm{L}$ ) than those with $50 \%$ or less mutant alleles [26]. This value for $\mathrm{CD} 34^{+}$cell level in PV was doubled in comparison to our result $\left(9.4 \times 10^{6} / \mathrm{L}\right)$ for PV patients with more than $50 \% J A K 2 \mathrm{~V} 617 \mathrm{~F}$ allele. In addition, according to our results ET patients regardless of JAK2 mutant alleles had higher circulating $\mathrm{CD} 34^{+}$counts than healthy individuals. Moreover, PMF patients had also increased level of circulating CD34 ${ }^{+}$ cells than healthy individuals, more elevated in patients with JAK2V617F allele.

Chronic inflammation may be an initiator of clonal evolution in patients with MPNs. The presence of elevated leukocyte and thrombocyte counts in MPNs may be the result of both clonal myeloproliferation and chronic inflammation presented by hypersensitivity to cytokine stimulation [27]. We demonstrated increased expression of JAK-STAT related genes and increased IL-6 levels in MPNs. IL-6-JAK1-STAT3 signal transduction pathway had an important role in the conversion of differentiated cancer cells into cancer stem cells [28]. Inhibition of JAK blocked IL-6-induced phosphorylation of STAT3 but failed to block the phosphorylation of mitogen-activated protein kinase (MAPK) [29]. Another major signaling pathway for IL-6-type cytokines was the MAPK cascade [2]. Soluble calreticulin induced proinflammatory cytokine IL-6 in macrophages via MAPKNF- $\kappa \mathrm{B}$ signaling pathway [30]. SOCS1 expression was elevated in MPN granulocytes but the level was independent of JAK2V617F mutational status. SOCS3 is an inhibitor of IL-6 and STAT3, regulated by DNA methylation. The transcript levels of SOCS3 were increased in granulocytes from JAK2V617F-positive MPN patients. Hypermethylation of the SOCS3 promoter was identified in 32\% of patients with PMF but not in patients with ET and PV [31].

We presented expression of genes related to inflammatory NF- $\kappa$ B and TGF- $\beta$ signaling in MPNs. IL- 6 transsignaling was dependent on STAT3 and mediated through enhanced TGF- $\beta$ signaling [4]. A dysregulation of NF- $\kappa$ B was already addressed as responsible for the MPNs [31]. NF- $\kappa \mathrm{B}$ dysregulation in microRNA-146a-deficient mice drove the development of myeloid malignancies. MicroRNA-146a has been implicated as a negative feedback regulator of NF- $\kappa \mathrm{B}$ activation. The mice also exhibited chronic myeloproliferation in their bone marrow, with increased transcription of NF$\kappa \mathrm{B}$-regulated genes [32]. NF- $\kappa \mathrm{B}$ was a central mediator of TGF- $\beta$ induction in monocytes from patients with PMF [33]. A spontaneous activation of NF- $\kappa \mathrm{B}$ was also detected in proliferating megakaryocytes and circulating $\mathrm{CD} 34^{+}$cells of patients with PMF, involved in TGF- $\beta 1$ secretion [34]. Patients with MPN had higher peripheral blood plasma levels of both bioactive and total TGF- $\beta 1$ compared to healthy controls [35]. TGFBR2 was significantly overexpressed in advanced PMF stages produced by endothelial cells of the increased microvessel network [36]. Expression of members of bone morphogenetic protein (BMP) family, BMP1, BMP6, BMP7, and BMP-receptor 2, was significantly increased in advanced stages of PMF [36]. Cytokine IL-10 had increased levels in plasma of PMF patients [8]. In our analysis, gene 
TABLE 4: Comparison of gene expression profiling between former and present studies in CD34 ${ }^{+}$cells of MPN subjects.

\begin{tabular}{|c|c|c|c|c|}
\hline Studies & Guglielmelli et al. [17] & Jones et al. [18] & Steidl et al. [19] & Čokić et al. \\
\hline MPN & PMF & PMF & PV & PV, ET, PMF \\
\hline Purified from & $\begin{array}{l}\text { PB-PMF } \\
\text { BM-HC }\end{array}$ & $\begin{array}{l}\text { PB-PMF } \\
\text { BM-HC }\end{array}$ & $\begin{array}{l}\text { BM-PMF } \\
\text { BM-HC }\end{array}$ & $\begin{array}{c}\text { PB-PV, ET, and PMF } \\
\text { PB-HC }\end{array}$ \\
\hline RNA & Pooled & $\begin{array}{c}\text { Amplified } 50 \mathrm{ng} \\
\text { of total RNA }\end{array}$ & Individual & $\begin{array}{c}\text { Amplified } 300 \mathrm{ng} \\
\text { of total RNA }\end{array}$ \\
\hline $\begin{array}{l}\text { Examined } \\
\text { MPN patients }\end{array}$ & $\begin{array}{l}\text { Mixed: de novo, } \\
\text { treated/paused }\end{array}$ & $\begin{array}{l}\text { Mixed: de novo, } \\
\text { treated/paused }\end{array}$ & De novo & De novo \\
\hline Number of patients & $\begin{array}{l}\text { PMF, } 3 \times 5 \\
\mathrm{HC}, 3 \times 5\end{array}$ & $\begin{array}{c}\text { PMF, } 8 \\
\mathrm{HC}, 6\end{array}$ & $\begin{array}{c}\mathrm{PV}, 4 \\
\mathrm{HC}, 10 \\
\end{array}$ & $\begin{array}{c}\text { PV, 7, ET, 9, } \\
\text { PMF, 4, and HC, } 8\end{array}$ \\
\hline $\begin{array}{l}\text { Microarray } \\
\text { chips }\end{array}$ & $\begin{array}{c}\text { Affymetrix HG-U133A } \\
\text { GeneChip }\end{array}$ & $\begin{array}{l}\text { Affymetrix HGU95Av2 } \\
\text { chip }\end{array}$ & $\begin{array}{c}\text { Atlas Clontech Human } \\
1.2 \mathrm{I}\end{array}$ & Operon Human Genome 4.0 \\
\hline $\begin{array}{l}\text { Number of examined } \\
\text { genes }\end{array}$ & $\begin{array}{c}16.000 \text { genes } \\
(22.238 \text { probes })\end{array}$ & $\begin{array}{c}9.670 \text { genes } \\
\text { (12.625 probes) }\end{array}$ & 1.185 genes & $\begin{array}{c}25.100 \text { genes } \\
\text { (35.035 probes) }\end{array}$ \\
\hline$J A K 2 \mathrm{~V} 617 \mathrm{~F}$ & $\begin{array}{l}\text { Mixture of } 8 \text { mutated } \\
\text { and } 7 \text { nonmutated }\end{array}$ & Not analyzed & Not analyzed & $\begin{array}{l}\text { Separated according to } \\
\text { mutant allele burden }\end{array}$ \\
\hline Characterized genes & 174 & $\begin{array}{l}95 \text { (48 upregulated and } \\
47 \text { downregulated) }\end{array}$ & 107 & $\begin{array}{l}\text { PV, 261, ET, } 82, \\
\text { PMF, } 94\end{array}$ \\
\hline
\end{tabular}

HC: healthy controls, PB: peripheral blood, and BM: bone marrow.

expression of receptor for IL-10 (IL10RB) was increased in $\mathrm{CD}_{3}{ }^{+}$cells of ET and PV and reduced in PMF with no statistical significance.

The recent JAK1/2 inhibitor trials in MPNs unexpectedly showed that reducing inflammation can be more beneficial to patients than targeting gene mutants [37]. Increased level of cytokine IL-6 was associated with shorter survival in patients with PMF [8]. The proportion of hematopoietic cells expressing the $J A K 2 \mathrm{~V} 617 \mathrm{~F}$ mutation decreased after in vitro differentiation of $\mathrm{CD} 34^{+}$cells in the presence of optimal concentration of IL- 6 and other growth factors [38]. Panobinostat, a pan-deacetylase inhibitor that depletes JAK2V617F levels and JAK/STAT signaling in MPN cells, reduced IL-6 level in plasma of PMF patients [39]. Moreover, IL-6 secreted by stromal cells protected JAK2V617F mutated cells, MPN clones, from JAK2 inhibitor therapy [40]. Siltuximab, a chimeric anti-IL-6 monoclonal antibody, did not reduce $\mathrm{RBC}$ transfusions in transfusion-dependent patients with low- and intermediate-1-risk myelodysplastic syndrome [41]. The addition of siltuximab to bortezomib did not improve progression-free or overall survival regardless of a numerical increase in response rate of patients with relapsed or refractory multiple myeloma [42]. The addition of siltuximab to bortezomib-melphalan-prednisone improved the complete response rate by $5 \%$, overall response rate by $8 \%$, and partial response rate by $20 \%$ in multiple myeloma [43]. Siltuximab in combination with dexamethasone yielded a partial response rate of $23 \%$ in patients with relapsed or refractory multiple myeloma [44].

For microarray analyses of CD $34^{+}$cells we used amplified RNA. Polacek et al. observed $94 \%$ overlap of the differentially expressed genes when starting with $100 \mathrm{ng}$ total RNA input in the amplification procedure [45]. Greater than 90\% overlap has been reported with oligo arrays when starting with $250 \mathrm{ng}$ total RNA input $[46,47]$. In addition, the quality of the array data was superior to that obtained using total RNA [48]. Therefore, we used $300 \mathrm{ng}$ total RNA input for amplification and it is couple times higher than or similar to the previous observations with more than $90 \%$ overlap. By this approach, we greatly reduced the possibility of biases in the relative representations of unique RNAs. Previous profile reports included various quantities of examined genes from purified CD34 ${ }^{+}$cells of PMF and PV subjects (Table 4) [1719]. We performed microarray studies with 25.100 genes in $\mathrm{CD}^{+} 4^{+}$cells from the peripheral blood of MPN subjects. According to different technical approaches, as presented in Table 4 (we prepared amplified RNA from peripheral blood of individual MPN patients and controls rather than performing pools of RNA from patient groups and bone marrow derived CD $34^{+}$cells), we found some minor overlap in differentially expressed genes. In microarray study of well characterized and significantly different genes performed by Guglielmelli et al., FGFR1, KLF4, and TGFBI levels were decreased, while IFITM1 level was increased in PMF CD34 ${ }^{+}$cells [17]. In our study, FGFR4, KLF2 gene expression was increased in $\mathrm{PV}$, augmented by JAK2V617F mutant allele burden, while TGFBI level was increased in PV and ET patients. IFITM1 level was also increased in our PV and ET CD34 ${ }^{+}$cells, enhanced by JAK2V617F mutant allele burden (Supplemental Table 1). In microarray study of Jones et al., TNFRSF1A and TGIF2-C20ORF24 were downregulated, while NCF2 gene expression was upregulated in PMF $\mathrm{CD} 34^{+}$cells [18]. In our study, NCF2 gene expression was upregulated in PV, while TNFRSF1A was upregulated in JAK2V617F positive ET patients. In gene expression profiling study by Steidl et al., CAPNS1, CASP1, GPX1, and HSPA8 were downregulated, while FGFR4, TGFBI, and IL-6 were upregulated in PV CD34 ${ }^{+}$cells [19]. In our study, CAPNS1 and HSPA8 were downregulated in PMF and PV, whereas CASP1, IL6ST, and GPX1 were upregulated in PV and ET, respectively; FGFR4 
was upregulated in PV patients, augmented by JAK2V617F allele burden. Therefore, the increased levels of inflammation biomarkers (TGFBI, IL-6) were also detected in previous microarray studies.

\section{Conclusion}

Besides determination of significantly changed genes in $\mathrm{CD} 34^{+}$cells of MPNs, we confirmed activation of JAK-STAT signaling related genes, such as CSF3R, IL6ST, PIM1, and $S T A T 1 / 2$. Regarding parameters of inflammation, leukocytosis was increased in PV and PMF, while thrombocytosis was reduced in ET and PMF with JAK2V617F mutation. Proinflammatory cytokine IL-6 levels were generally increased in peripheral blood and bone marrow of patients with MPN but were more prominent in JAK2V617F mutation positive ET and PMF patients. Therefore, JAK2V617F mutant allele burden participated in inflammation biomarkers induction. The presented inflammation biomarkers will provide a better understanding of molecular mechanisms implicated in the development and progression of MPNs.

\section{Conflict of Interests}

The authors declare that there is no conflict of interests regarding the publication of this paper.

\section{Authors' Contribution}

Vladan P. Čokić, Olivera Mitrović-Ajtić, Bojana B. BeleslinČokić, Dragana Marković, Marijana Buač, Miloš Diklić, and Nada Kraguljac-Kurtović performed the research; Vladan P. Cokić, Pavle Milenković, and Puri K. Raj designed the research; Svetozar Damjanović, Mirjana Gotić, Puri K. Raj, and Nada Kraguljac-Kurtović contributed essential reagents or tools; Vladan P. Čkić, Olivera Mitrović-Ajtić, Bojana B. Beleslin-Čokić, Dragana Marković, and Marijana Buač analyzed the data; Vladan P. Čokić wrote the paper; and Pavle Milenković, Mirjana Gotić, and Puri K. Raj revised the paper.

\section{Acknowledgments}

This research was supported by Intramural Research Program of Alan N. Schechter at the National Institute of Diabetes and Digestive and Kidney Diseases, NIH, Bethesda, and by a Grant from the Serbian Ministry of Education, Science and Technological Development (no. 175053).

\section{References}

[1] G. Landskron, M. De La Fuente, P. Thuwajit, C. Thuwajit, and M. A. Hermoso, "Chronic inflammation and cytokines in the tumor microenvironment," Journal of Immunology Research, vol. 2014, Article ID 149185, 19 pages, 2014.

[2] P. C. Heinrich, I. Behrmann, S. Haan, H. M. Hermanns, G. Müller-Newen, and F. Schaper, "Principles of interleukin (IL)6-type cytokine signalling and its regulation," The Biochemical Journal, vol. 374, no. 1, pp. 1-20, 2003.
[3] J. J. Babon, L. N. Varghese, and N. A. Nicola, "Inhibition of IL-6 family cytokines by SOCS3," Seminars in Immunology, vol. 26, no. 1, pp. 13-19, 2014.

[4] S. O’Reilly, M. Ciechomska, R. Cant, and J. M. Van Laar, "Interleukin-6 (IL-6) trans signaling drives a STAT3-dependent pathway that leads to hyperactive transforming growth factor$\beta$ (TGF- $\beta$ ) signaling promoting SMAD3 activation and fibrosis via gremlin protein," The Journal of Biological Chemistry, vol. 289, no. 14, pp. 9952-9960, 2014.

[5] K. Heikkilä, S. Ebrahim, and D. A. Lawlor, "Systematic review of the association between circulating interleukin-6 (IL-6) and cancer," European Journal of Cancer, vol. 44, no. 7, pp. 937-945, 2008.

[6] C. Mirantes, E. Passegué, and E. M. Pietras, "Pro-inflammatory cytokines: emerging players regulating HSC function in normal and diseased hematopoiesis," Experimental Cell Research, vol. 329, no. 2, pp. 248-254, 2014.

[7] K. E. Panteli, E. C. Hatzimichael, P. K. Bouranta et al., "Serum interleukin (IL)-1, IL-2, sIL-2Ra, IL-6 and thrombopoietin levels in patients with chronic myeloproliferative diseases," British Journal of Haematology, vol. 130, no. 5, pp. 709-715, 2005.

[8] A. Tefferi, R. Vaidya, D. Caramazza, C. Finke, T. Lasho, and A. Pardanani, "Circulating interleukin (IL)-8, IL-2R, IL-12, and IL15 levels are independently prognostic in primary myelofibrosis: a comprehensive cytokine profiling study," Journal of Clinical Oncology, vol. 29, no. 10, pp. 1356-1363, 2011.

[9] H.-C. Hsu, W.-H. Tsai, M.-L. Jiang et al., "Circulating levels of thrombopoietic and inflammatory cytokines in patients with clonal and reactive thrombocytosis," Journal of Laboratory and Clinical Medicine, vol. 134, no. 4, pp. 392-397, 1999.

[10] C. Wickenhauser, J. Thiele, J. Lorenzen et al., "Polycythemia vera megakaryocytes but not megakaryocytes from normal controls and patients with smokers polyglobuly spontaneously express IL-6 and IL-6R and secrete IL-6," Leukemia, vol. 13, no. 3, pp. $327-334,1999$.

[11] C. Lee, H.-K. Lim, J. Sakong, Y.-S. Lee, J.-R. Kim, and S.H. Baek, "Janus kinase-signal transducer and activator of transcription mediates phosphatidic acid-induced interleukin (IL)-1 $\beta$ and IL-6 production," Molecular Pharmacology, vol. 69, no. 3, pp. 1041-1047, 2006.

[12] M. Colomiere, A. C. Ward, C. Riley et al., "Cross talk of signals between EGFR and IL-6R through JAK2/STAT3 mediate epithelial-mesenchymal transition in ovarian carcinomas," British Journal of Cancer, vol. 100, no. 1, pp. 134-144, 2009.

[13] T. L. Lee, J. Yeh, C. Van Waes, and Z. Chen, "Epigenetic modification of SOCS-1 differentially regulates STAT3 activation in response to interleukin- 6 receptor and epidermal growth factor receptor signaling through JAK and/or MEK in head and neck squamous cell carcinomas," Molecular Cancer Therapeutics, vol. 5, no. 1, pp. 8-19, 2006.

[14] A. Quintás-Cardama, K. Vaddi, P. Liu et al., "Preclinical characterization of the selective JAK1/2 inhibitor INCB018424: therapeutic implications for the treatment of myeloproliferative neoplasms," Blood, vol. 115, no. 15, pp. 3109-3117, 2010.

[15] A. Kirabo, S. O. Park, A. Majumder et al., "The Jak2 inhibitor, G6, alleviates Jak2-V617F-mediated myeloproliferative neoplasia by providing significant therapeutic efficacy to the bone marrow," Neoplasia, vol. 13, no. 11, pp. 1058-1068, 2011.

[16] C. Lee, J.-I. Oh, J. Park et al., "TNF $\alpha$ mediated IL-6 secretion is regulated by JAK/STAT pathway but not by MEK phosphorylation and AKT phosphorylation in U266 multiple myeloma 
cells," BioMed Research International, vol. 2013, Article ID 580135, 8 pages, 2013.

[17] P. Guglielmelli, R. Zini, C. Bogani et al., "Molecular profiling of $\mathrm{CD} 34^{+}$cells in idiopathic myelofibrosis identifies a set of disease-associated genes and reveals the clinical significance of Wilms' tumor gene 1 (WT1)," Stem Cells, vol. 25, no. 1, pp. 165173, 2007.

[18] L. C. Jones, A. Tefferi, P. T. Vuong, J. C. Desmond, W.-K. Hofmann, and H. P. Koeffler, "Detection of aberrant gene expression in $\mathrm{CD}_{3} 4^{+}$hematopoietic stem cells from patients with agnogenic myeloid metaplasia using oligonucleotide microarrays," Stem Cells, vol. 23, no. 5, pp. 631-637, 2005.

[19] U. Steidl, T. Schroeder, C. Steidl et al., "Distinct gene expression pattern of malignant hematopoietic stem and progenitor cells in polycythemia vera," Annals of the New York Academy of Sciences, vol. 1044, pp. 94-108, 2005.

[20] A. Tefferi, E. Rumi, G. Finazzi et al., "Survival and prognosis among 1545 patients with contemporary polycythemia vera: an international study," Leukemia, vol. 27, no. 9, pp. 1874-1881, 2013.

[21] G. Bonicelli, K. Abdulkarim, M. Mounier et al., "Leucocytosis and thrombosis at diagnosis are associated with poor survival in polycythaemia vera: a population-based study of 327 patients," British Journal of Haematology, vol. 160, no. 2, pp. 251-254, 2013.

[22] T. Barbui, A. Carobbio, F. Cervantes et al., "Thrombosis in primary myelofibrosis: incidence and risk factors," Blood, vol. 115, no. 4, pp. 778-782, 2010.

[23] A. Enblom, E. Lindskog, H. Hasselbalch et al., "High rate of abnormal blood values and vascular complications before diagnosis of myeloproliferative neoplasms," European Journal of Internal Medicine, vol. 26, no. 5, pp. 344-347, 2015.

[24] E. Pourcelot, C. Trocme, J. Mondet, S. Bailly, B. Toussaint, and P. Mossuz, "Cytokine profiles in polycythemia vera and essential thrombocythemia patients: clinical implications," Experimental Hematology, vol. 42, no. 5, pp. 360-368, 2014.

[25] F. Passamonti, L. Vanelli, L. Malabarba et al., "Clinical utility of the absolute number of circulating CD34-positive cells in patients with chronic myeloproliferative disorders," Haematologica, vol. 88, no. 10, pp. 1123-1129, 2003.

[26] F. Passamonti, E. Rumi, D. Pietra et al., "Relation between JAK2 (V617F) mutation status, granulocyte activation, and constitutive mobilization of $\mathrm{CD} 34^{+}$cells into peripheral blood in myeloproliferative disorders," Blood, vol. 107, no. 9, pp. 3676$3682,2006$.

[27] H. C. Hasselbalch, "Perspectives on chronic inflammation in essential thrombocythemia, polycythemia vera, and myelofibrosis: is chronic inflammation a trigger and driver of clonal evolution and development of accelerated atherosclerosis and second cancer?" Blood, vol. 119, no. 14, pp. 3219-3225, 2012.

[28] S.-Y. Kim, J. W. Kang, X. Song et al., "Role of the IL-6-JAK1STAT3-Oct-4 pathway in the conversion of non-stem cancer cells into cancer stem-like cells," Cellular Signalling, vol. 25, no. 4, pp. 961-969, 2013.

[29] P. Kothari, R. Pestana, R. Mesraoua et al., "IL-6-mediated induction of matrix metalloproteinase- 9 is modulated by JAKdependent IL-10 expression in macrophages," The Journal of Immunology, vol. 192, no. 1, pp. 349-357, 2013.

[30] C.-C. Duo, F.-Y. Gong, X.-Y. He et al., "Soluble calreticulin induces tumor necrosis factor- $\alpha$ (TNF- $\alpha$ ) and interleukin (IL)-6 production by macrophages through mitogen-activated protein kinase (MAPK) and NFKB signaling pathways," International Journal of Molecular Sciences, vol. 15, no. 2, pp. 2916-2928, 2014.
[31] N. Fourouclas, J. Li, D. C. Gilby et al., "Methylation of the suppressor of cytokine signaling 3 gene (SOCS3) in myeloproliferative disorders," Haematologica, vol. 93, no. 11, pp. 1635-1644, 2008.

[32] J. L. Zhao, D. S. Rao, M. P. Boldin, K. D. Taganov, R. M. O'Connell, and D. Baltimore, "NF-kappaB dysregulation in microRNA-146a-deficient mice drives the development of myeloid malignancies," Proceedings of the National Academy of Sciences of the United States of America, vol. 108, no. 22, pp. 9184-9189, 2011.

[33] P. Rameshwar, R. Narayanan, J. Qian, T. N. Denny, C. Colon, and P. Gascon, "NF- $\kappa \mathrm{B}$ as a central mediator in the induction of TGF- $\beta$ in monocytes from patients with idiopathic myelofibrosis: an inflammatory response beyond the realm of homeostasis," Journal of Immunology, vol. 165, no. 4, pp. 22712277,2000

[34] E. Komura, C. Tonetti, V. Penard-Lacronique et al., "Role for the nuclear factor kappaB pathway in transforming growth factor-betal production in idiopathic myelofibrosis: possible relationship with FK506 binding protein 51 overexpression," Cancer Research, vol. 65, no. 8, pp. 3281-3289, 2005.

[35] R. Campanelli, V. Rosti, L. Villani et al., "Evaluation of the bioactive and total transforming growth factor $\beta 1$ levels in primary myelofibrosis," Cytokine, vol. 53, no. 1, pp. 100-106, 2011.

[36] O. Bock, J. Höftmann, K. Theophile et al., "Bone morphogenetic proteins are overexpressed in the bone marrow of primary myelofibrosis and are apparently induced by fibrogenic cytokines," The American Journal of Pathology, vol. 172, no. 4, pp. 951-960, 2008.

[37] F. P. S. Santos and S. Verstovsek, "JAK2 inhibitors for myelofibrosis: why are they effective in patients with and without JAK2V617F mutation?" Anti-Cancer Agents in Medicinal Chemistry, vol. 12, no. 9, pp. 1098-1109, 2012.

[38] T. Ishii, E. Bruno, R. Hoffman, and M. Xu, "Involvement of various hematopoietic-cell lineages by the JAK2 V617F mutation in polycythemia vera," Blood, vol. 108, no. 9, pp. 31283134, 2006.

[39] D. J. Deangelo, R. A. Mesa, W. Fiskus et al., "Phase II trial of panobinostat, an oral pan-deacetylase inhibitor in patients with primary myelofibrosis, post-essential thrombocythaemia, and post-polycythaemia vera myelofibrosis," British Journal of Haematology, vol. 162, no. 3, pp. 326-335, 2013.

[40] T. Manshouri, Z. Estrov, A. Quintás-Cardama et al., "Bone marrow stroma-secreted cytokines protect JAK2V617F-mutated cells from the effects of a JAK2 inhibitor," Cancer Research, vol. 71, no. 11, pp. 3831-3840, 2011.

[41] G. Garcia-Manero, G. Gartenberg, D. P. Steensma et al., "A phase 2, randomized, double-blind, multicenter study comparing siltuximab plus best supportive care (BSC) with placebo plus BSC in anemic patients with International Prognostic Scoring System low- or intermediate-1-risk myelodysplastic syndrome," American Journal of Hematology, vol. 89, no. 9, pp. E156-E162, 2014.

[42] R. Z. Orlowski, L. Gercheva, C. Williams et al., "A phase 2, randomized, double-blind, placebo-controlled study of siltuximab (anti-IL-6 mAb) and bortezomib versus bortezomib alone in patients with relapsed or refractory multiple myeloma," American Journal of Hematology, vol. 90, no. 1, pp. 42-49, 2015.

[43] J. San-Miguel, J. Bladé, O. Shpilberg et al., "Phase 2 randomized study of bortezomib-melphalan-prednisone with or without siltuximab (anti-IL-6) in multiple myeloma," Blood, vol. 123, no. 26, pp. 4136-4142, 2014. 
[44] P. M. Voorhees, R. F. Manges, P. Sonneveld et al., "A phase 2 multicentre study of siltuximab, an anti-interleukin- 6 monoclonal antibody, in patients with relapsed or refractory multiple myeloma," British Journal of Haematology, vol. 161, no. 3, pp. 357-366, 2013.

[45] D. C. Polacek, A. G. Passerini, C. Shi et al., "Fidelity and enhanced sensitivity of differential transcription profiles following linear amplification of nanogram amounts of endothelial mRNA," Physiological Genomics, vol. 13, no. 2, pp. 147-156, 2003.

[46] M. G. Carter, T. Hamatani, A. A. Sharov et al., "In situsynthesized novel microarray optimized for mouse stem cell and early developmental expression profiling," Genome Research, vol. 13, no. 5, pp. 1011-1021, 2003.

[47] S. Klur, K. Toy, M. P. Williams, and U. Certa, "Evaluation of procedures for amplification of small-size samples for hybridization on microarrays," Genomics, vol. 83, no. 3, pp. 508517, 2004.

[48] A. L. Feldman, N. G. Costouros, E. Wang et al., "Advantages of mRNA amplification for microarray analysis," BioTechniques, vol. 33, no. 4, pp. 906-914, 2002. 


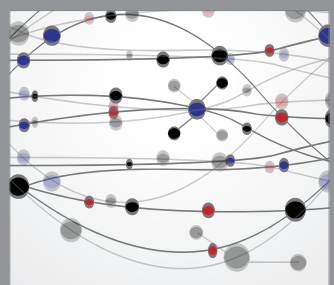

The Scientific World Journal
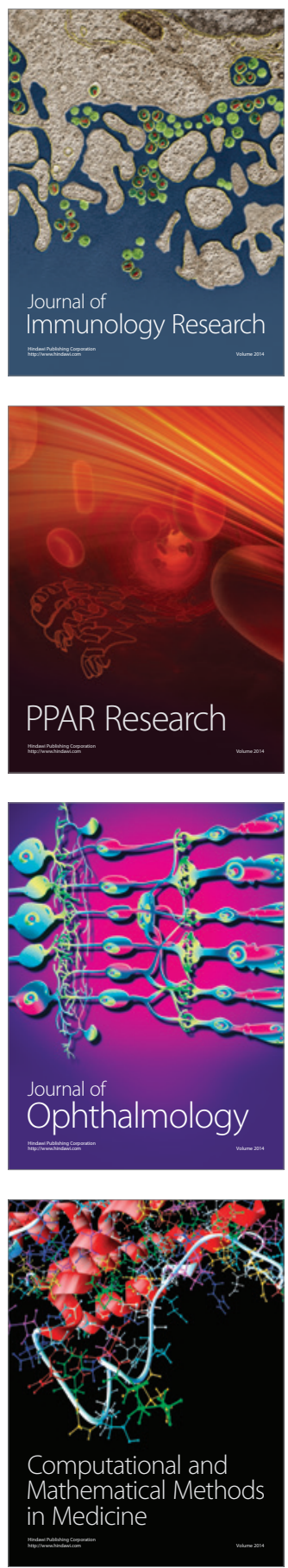

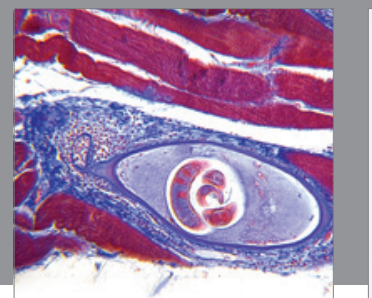

Gastroenterology

Research and Practice
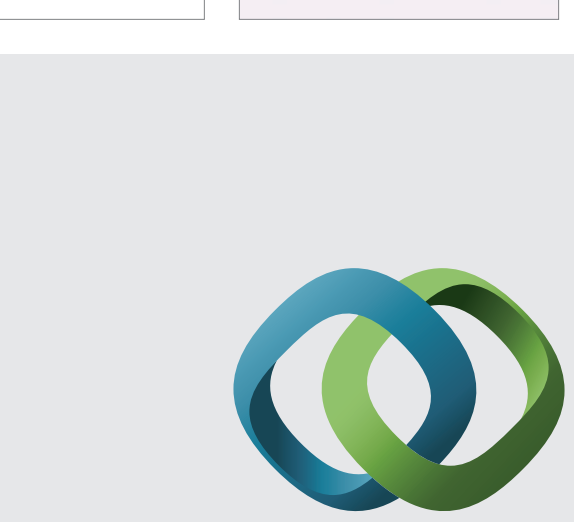

\section{Hindawi}

Submit your manuscripts at

http://www.hindawi.com
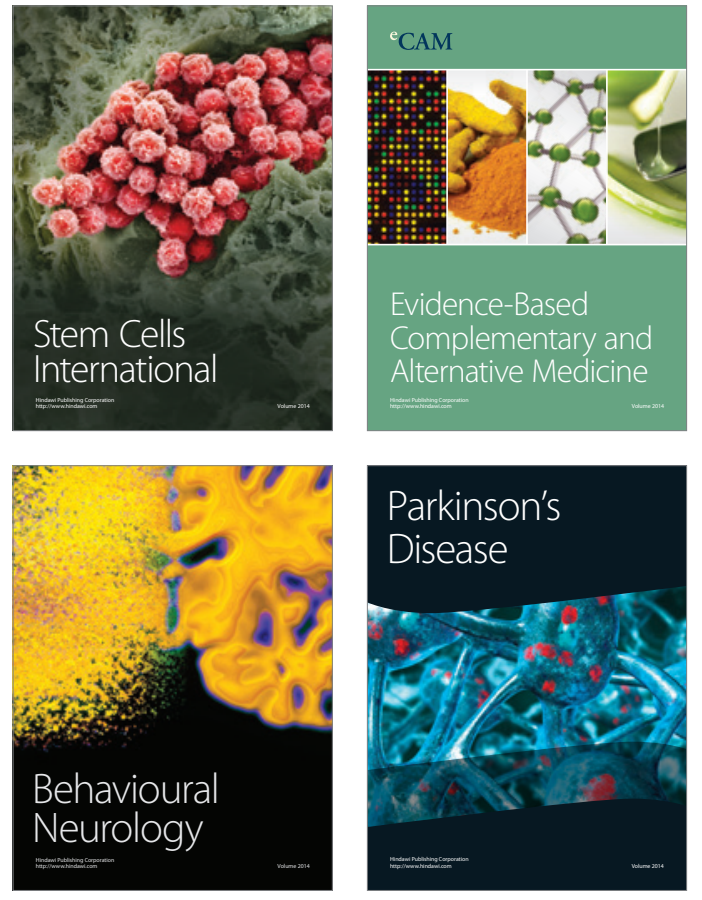
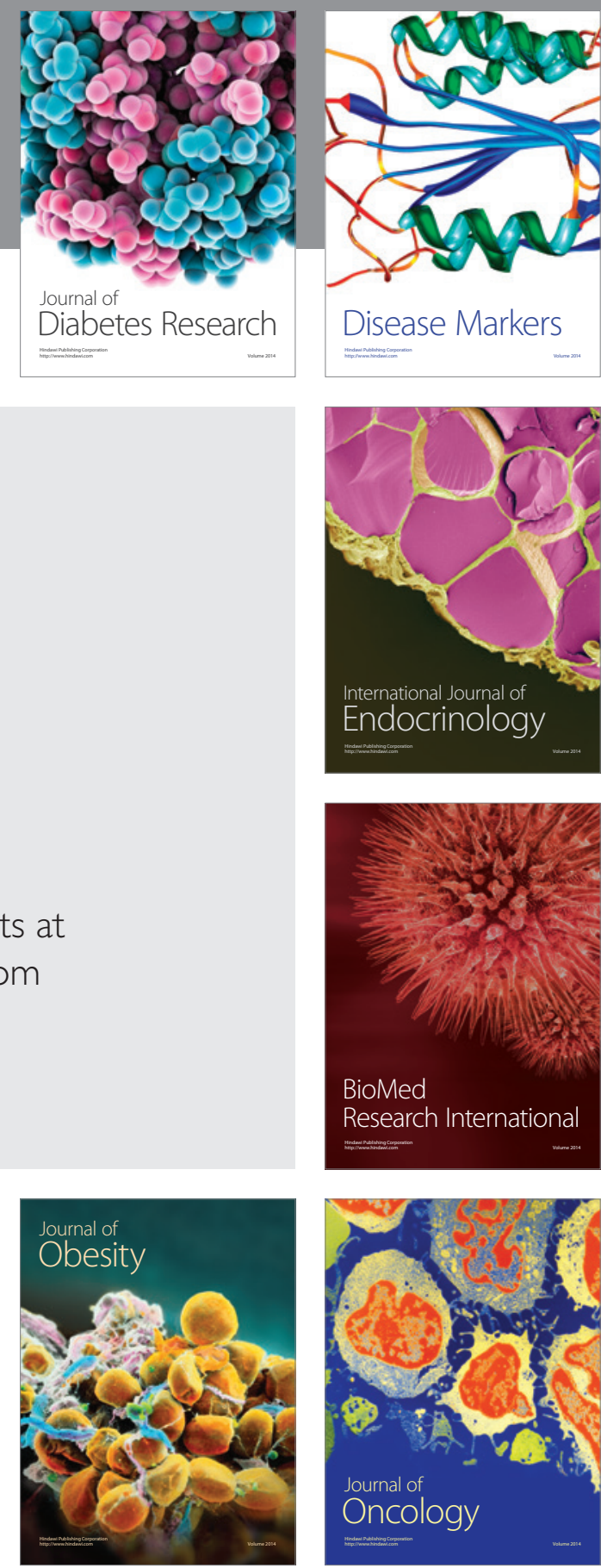

Disease Markers
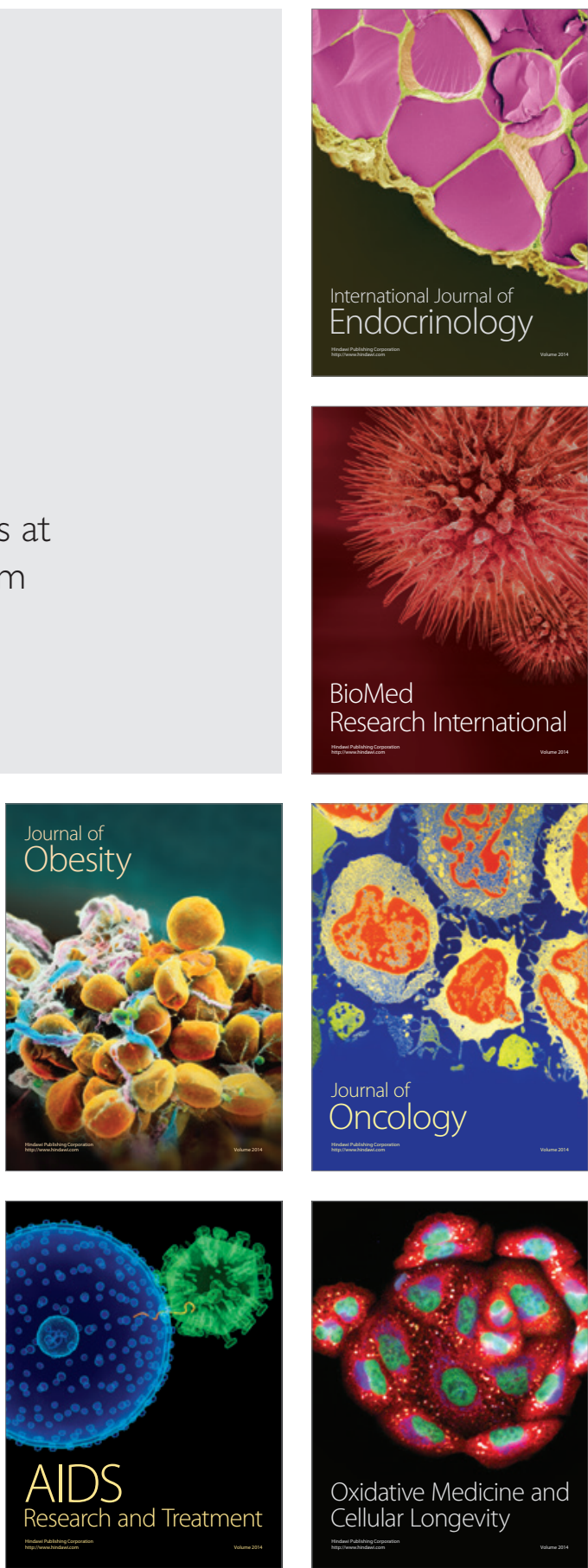